\title{
Música, memória e história na obra de Eduardo Coutinho
}

\section{Music, memory, and history in the work of Eduardo Coutinho}

Renato Levi ${ }^{1}$ 
Resumo

A música é um dos elementos fundamentais na construção e resgate das memórias pessoais e históricas. Eduardo Coutinho, notável cineasta que desenvolveu grande parte de sua filmografia se dedicando à escuta de seus interlocutores, foi muito além de um "cinema da palavra". Para ele, o "ato verbal", por vezes, incluía a música como elemento expressivo essencial para acessar e reconstruir a história de cada um.

Palavras-chave

Música, memória, Eduardo Coutinho.

\section{Abstract}

Music is a key component in the process of making and recovering personal and historical memories. Eduardo Coutinho, remarkable filmmaker whose films were mostly based on conversations with characters, went far beyond the "word-spoken cinema". In his work, the so-called "verbal act" would also include music as an essential element of expression, a fundamental way to access and reconstruct personal histories.

\section{Keywords}

Music, memory, Eduardo Coutinho. 


\section{A música de cada um}

Para a humanidade, a música é uma presença praticamente atemporal e universal. Pode-se dizer que a música é inata aos humanos e que sua origem se confunde com a da linguagem falada. Cada uma dessas formas de expressão nos acompanha desde muito cedo, e é responsável tanto por construir os aspectos generalizantes que definem as tradições quanto as particularidades que definem a trajetória de cada indivíduo. Música, em especial, tem um papel fundamental na construção das identidades pessoais e coletivas, na constituição das nacionalidades e na afirmação de diferentes culturas.

Desde os tempos ancestrais, a vivência da música era apenas uma possibilidade a ser experimentada de forma presencial. A partir da modernidade, o modo como se faz e se consome música passa por enormes e radicais transformações. De uma fruição de caráter majoritariamente comunitário e ritualística, a música passa a contar com novos meios de registro, divulgação e difusão, que a direcionam a novas modalidades de experimentação, cujos resultados mais visíveis são, paradoxalmente, a popularização do consumo e a potencialização de um usufruto individualizado. Essa trajetória é consubstanciada pela tecnologia crescente dos aparatos de reprodução sonora e pelo desenvolvimento e pela abrangência dos meios massivos de comunicação, inicialmente com o rádio e o cinema e, em seguida, com o disco e a TV. Tal processo se acentua com o advento da internet e da digitalização, que multiplicam os meios e dispositivos capazes de oferecer acesso a qualquer música a qualquer hora e em qualquer lugar. Nesse sentido, o consumo de música adquire características controversas, podendo ser, por um lado resultado sintomático das pressões engendradas pela indústria cultural, e, por outro, resultado de espaços criados pela demarcação de campos de questionamento e resistência.

Se a vivência da música, em seus primeiros momentos, foi fruto de atividades praticadas em grupo e, consequentemente, dirigidas ao coletivo, com os novos meios tecnológicos ela passa a se direcionar a um ouvinte cada vez mais individualizado e autônomo. Com isso, a música vai agregando significados 
cada vez mais específicos e singulares, enriquecendo emocional e esteticamente a história particular de cada indivíduo.

\section{A trilha sonora da vida}

Podemos dizer que as definições e alternâncias dos componentes emocionais e estéticos de nossas experiências com a música vão construindo a "trilha sonora da vida". As nossas vivências musicais, iniciadas na infância, vão aos poucos engendrando a formação do gosto e dando forma a nossa capacidade de fruição estética. São processos híbridos nos quais operam componentes racionais e subjetivos, individuais e coletivos e que em suas interrelações moldam nossa identidade. As músicas de ninar são, a princípio, parte de um arcabouço cultural coletivo, mas também possuem relações com o ambiente estético específico de cada família. Nas fases subsequentes da vida, a música passa a ocupar outros lugares ligados à diversidade e multiplicidade dos novos contextos vivenciados os amigos, a escola, o trabalho, os afetos, os diferentes ambientes frequentados e a exposição aos produtos da indústria cultural. Podemos, então, dizer que nas significações que a música adquire desdobram-se camadas semânticas do pessoal e do coletivo, do subjetivo e do objetivo, do lírico e do épico. A mesma música ou canção pode adquirir uma gama complexa e variável de sentidos dependendo do contexto de sua enunciação e das referências individuais de cada ouvinte.

\section{Música e memória}

São diversas as evidências de que a linguagem musical ocupa um lugar singular nas nossas capacidades ligadas à memória. Diferentemente de outros estímulos percebidos pelos nossos sentidos, as músicas são comumente "armazenadas" de forma mais íntegra, preservadas por meio de suas estruturas rítmico-melódicas. A música é atrelada à orientação temporal de seu discurso que engendra em si uma narrativa estruturada e coesa. Sabe-se que o fabular e o narrar organizam fatos e memórias ajudando a cristalizar histórias, mitos, 
metafísicas, contos e cantos. O fato de a música se organizar como narrativa permite o seu armazenamento e, talvez, explique o porquê das memórias musicais geralmente reaparecem mais preservadas. Já as lembranças adquiridas pelos outros sentidos são, em geral, guardadas e recuperadas de modo mais fragmentado.

Os trabalhos do neurologista inglês Oliver Sacks reforçam esta ideia de que a forma da música se articula de maneira privilegiada com as estruturas do cérebro responsáveis pela memória, sendo armazenada e relembrada de maneira única. De fato, muito frequentemente experimentamos o retorno súbito e íntegro de músicas da nossa memória mesmo depois de décadas da última vez que ouvimos, assim como é comum ouvir ou mesmo relembrar uma música e ser imediatamente remetido a sentimentos e memórias pessoais adquiridas no percurso da vida. Ademais, é importante mencionar os notáveis resultados do uso da música em diversos tipos de terapias com idosos acometidos ou não de demências ${ }^{2}$. Ao escutar as músicas que fizeram parte de suas vidas, muitas dessas pessoas recuperam, com resultados bastante surpreendentes, memórias, emoções bem como capacidades cognitivas e motoras. Esses são apenas alguns exemplos das evidências da sinergia entre a linguagem musical e os recursos da memória humana.

O que parece dar uma espécie de sentido e hierarquia à organização do repertório de memórias e sons é a emoção. Toda memória é, de alguma forma, articulada aos sentimentos vivenciados no contexto em que se dão os fatos. Quando se solicita ao cérebro que recupere tais eventos, estes, necessariamente, virão acompanhados de toda camada emotiva a eles ligada. Isso explica a razão pela qual, em geral, momentos de forte emoção ficam indelevelmente marcados na memória. No caso da música, a audição ou mesmo a lembrança das melodias 
e canções, que pertencem ao repertório valorável de cada ouvinte, recuperam memórias e emoções de forma intuitiva. É como se a música pudesse representar metaforicamente os sentimentos e as recordações.

\section{A memória de Eduardo Coutinho}

A obra cinematográfica documental de Eduardo Coutinho é notável pela capacidade de articulação verbal e também musical dos personagens, que ali encontram terreno fértil para uma expressão de si talvez nunca antes possível. A presença de uma câmera e de um interlocutor atento e sensível engendram uma interação privilegiada. Essa atmosfera incomum que a princípio pode intimidar, nos filmes de Coutinho, surpreendentemente, favorece a expressividade do entrevistado que se sente motivado e empoderado, protagonista único da sua história. Elencar fatos e sentimentos, na dinâmica dos diálogos propostos pelo diretor, favorece a recuperação das memórias mais significativas. As emoções qualificam e ordenam os fatos a elas associadas.

Fica evidente, nos mecanismos de acesso e verbalização das memórias vividas, a existência de uma dose de fabulação e "recriação" que pode chegar até a invenção de fatos. Isso é característico da memória que, como não pode lembrar de tudo com precisão, se fixa em determinados fragmentos, acontecimentos e sentimentos, atribuindo e "construindo" para estes um sentido valorável e único. Para Eduardo Coutinho, respeitar essa possível dose de "invenção" presente nos depoimentos dos personagens de seus filmes era fundamental. Não importava tanto chegar a uma objetividade improvável e utópica dos fatos, mas, sim, na forma pela qual eles foram individualmente vivenciados, sentidos e revisitados no momento das gravações. Essa busca para além da objetividade é o que distingue e distancia a obra de Coutinho da entrevista protocolar banalizada pela televisão. Aliás, o próprio autor fazia questão de demarcar território ao se distanciar dos cânones do jornalismo³. 


\section{A música popular do Brasil}

A despeito de um nível baixo de letramento e da prevalência de uma tradição baseada na cultura oral no Brasil, nossa canção trafega entre o popular e o erudito e está repleta da mais fina poesia e prosa ${ }^{4}$. Essas características propiciam uma música popular riquíssima, capaz de engendrar e expressar uma imensa gama de lirismo e sentimento na medida em que é apropriada como a trilha sonora de cada ouvinte. Além disso, o Brasil possui dimensões continentais e a persistência de desigualdades regionais e nacionais favorece a convivência de uma infinidade de cenários musicais que se influenciam e se interpenetram ${ }^{5}$.

A indústria cultural reflete cada vez menos a música de qualidade, a produção independente e a tradição histórica de nossa música popular, porém, garantem uma expressividade vibrante e, consequentemente, uma memória musical de grande alcance estético e significância ímpar. Essa música engendra uma espécie de trilha sonora do país que é sintomática de sua diversidade antropofágica e das inúmeras fragmentações regionais e sociais.

\section{A música de Eduardo Coutinho}

O cinema de Eduardo Coutinho possui uma trajetória considerável em, pelo menos, três aspectos que interagem e se complementam. Inicialmente, no aprimoramento de uma escuta privilegiada de depoimentos sempre surpreendentes. Também na experimentação constante de uma linguagem que caminha na direção da sobriedade e do comedimento no uso sempre econômico dos recursos audiovisuais. E, finalmente, no que diz respeito a um 
aspecto mais difuso, de certa forma contraditório e subversivo em sua obra: Coutinho soube inovar em seu percurso, reinventando dispositivos e recursos, conquistando ainda mais a sensibilidade de personagens e público e atingindo novas camadas de expressividade. Esses aspectos resultam em uma filmografia poderosa e única, capaz de acessar e produzir memórias com qualidade e emoção ímpares.

Apesar de ser comumente reconhecido como um cineasta da palavra, a canção brasileira permeia toda cinematografia de Eduardo Coutinho. Essa relação não é tão evidente, já que grande parte de sua trajetória foi construída com a produção de documentários em que prevalece o depoimento de personagens como principal recurso expressivo. São inúmeros os teóricos e críticos que se debruçaram sobre seu trabalho, sendo consenso que a construção de sua obra é famosa por dar espaço privilegiado ao verbo e ao "corpo que fala" e que esses elementos constituíram um dos ingredientes centrais de sua cinematografia. Mais rara, no entanto, é a avaliação de indícios de que paralelamente à palavra, à música e, especificamente, à canção também estiveram ali, sempre presentes, ainda que de forma mais discreta.

Em seu artigo Aspectos da música no documentário brasileiro contemporâneo: algumas reflexões sobre o fazer e o pensar, Guilherme Maia faz extensa revisão bibliográfica sobre as questões que envolvem a relação da música com os documentários. O autor demonstra que apesar da trilha sonora ser um recurso amplamente utilizado, existe uma tendência a relacionar a música não diegética em documentários com recursos diversionistas que visariam amplificar o caráter ficcional da narrativa. Como resultado, a música poderia, por exemplo, acentuar a emotividade da narrativa e, dessa forma, acabar comprometendo uma suposta objetividade: "Está posto em xeque o uso da música como estratégia de manipulação do espectador, como ferramenta subjetiva de persuasão, de cooptação para um determinado posicionamento ideológico ou afetivo em relação ao real representado" (MAIA, 2012, p. 114). 
Nesse sentido, a filmografia de Coutinho caminha no sentido de privilegiar a música diegética contextualizada, seguindo a lógica da interlocução com os fatos e personagens de seus filmes. Assim, as músicas acompanham a narrativa dos encontros, surgindo a partir de uma fala ou mesmo de uma solicitação do realizador.

Consuelo Lins, em O documentário de Eduardo Coutinho: televisão, cinema e vídeo, faz considerações sobre a poética musical do autor falando sobre o filme Santa Marta: duas semanas no morro, de 19876:

\begin{abstract}
Santa Marta possui uma trilha sonora singular, e talvez seja o documentário mais musical ${ }^{7}$ de Eduardo Coutinho. Ele insere na montagem final oito sequências com músicas de compositores do próprio morro, algumas incluindo a composição inteira. Os temas são variados: letras que idealizam a favela, letras românticas, que falam de religião, letras realistas (menor abandonado, invasão da polícia no morro, bebedeira), ou que afirmam a raiz africana. A utilização de uma trilha sonora essencialmente "local" se transformará em um princípio bastante rigoroso nos filmes de Coutinho. Pouco a pouco ele eliminará qualquer música que não esteja ligada ao ambiente filmado e que não tenha sido captada pela equipe técnica no local. Adicionar uma trilha traduz, segundo Coutinho, a opinião do diretor sobre aquele universo, conota algo, conduz o público, e eu não quero conotar nada. Prefiro a riqueza estética do som direto (LINS, 2004, p. 63).
\end{abstract}

Em Boca de Lixo, de 19938, a equipe visita a casa de uma das personagens que apresenta a sua família e, por fim, diz querer que "Deus dê uma chance a sua filha para que ela possa seguir o que quer". Com esse gancho, Coutinho passa a entrevistar a jovem que relata o desejo de ser cantora. O documentarista pergunta o que ela gosta de cantar e após a resposta - "música sertaneja" -

6 Disponível em: <https://vimeo.com/17346480>.

7 O livro é de 2004, portanto, anterior ao filme As canções. Acompanha 40 anos da trajetória de Eduardo Coutinho, em que são analisados todos os filmes do diretor, desde o premiado Cabra marcado para morrer (1964-84) até Peões (2004). 
segue-se uma performance musical que depois transforma-se em um videoclipe de imagens da vida daquela família. Ao analisar essa sequência, em um encontro mediado por Ilana Feldman ${ }^{9}$, Coutinho adjetiva a cantoria como extraordinária e relata que queria "cada vez mais...... só gente cantando, mas não dá, porque tem os direitos (autorais)". Ele, então, ressalta que o importante é o valor afetivo envolvido em tais momentos. Em seguida, conta que a garota processou a produção, pois, à época das filmagens, não era costume solicitar uma autorização de uso de imagem e som.

Edifício Master, de $2002^{10}$, é um filme cuja produção inicialmente foi marcada por uma crise devido aos personagens, durante a pesquisa, parecerem apáticos, "sem conflito". À época, a equipe do filme considerou que o problema poderia vir do fato de que, pela primeira vez, Coutinho lidava com a classe média. Os personagens entrevistados na fase de sondagem se mostraram, a princípio, ressabiados e desinteressados. Apesar de toda insegurança que marcou a fase inicial, o filme afinal aconteceu. Temos um acesso privilegiado ao processo de produção desse documentário a partir do filme Apartamento $608^{11}$, de Beth Formaginni, que acompanha os bastidores da produção de Edifício Master ${ }^{12}$. Nesse filme, podemos vislumbrar alguns momentos sintomáticos da relação visceral que Coutinho desenvolvia com seus personagens. No documentário, também estão evidentes as eloquentes e entusiasmadas manifestações de Coutinho sempre que, durante uma de suas conversas, surgia qualquer possibilidade de se abordar aspectos musicais. Ao examinar uma lista de canções diante de um de seus Coutinho. Gravação da conversa de Ilana Feldman com Eduardo Coutinho na Casa do Saber do Rio de Janeiro em abril de 2009. Disponível em: <https://www.youtube.com/watch?v=jbJi_S_St88>. 
personagens, ele pergunta: "Estas músicas, você sabe de cor? [...] você sabe cantar Perfídia?" O interlocutor Paulo Mata afirma que 'guardou em ritmo de...' e Coutinho o interrompe eufórico: "[se entende que a gravação da câmera principal ainda não havia começado de fato] 'você vai cantar pra[SIC] mim! Faço cinema há vinte anos para conseguir uma pessoa que cante Perfídia para mim! Você vai cantar para mim!'"13.

Além desse diálogo com Paulo Mata, antes da filmagem, em Edifício Master são diversos os personagens que cantam. Um dos pontos mais emocionantes do filme é, sem dúvida, o depoimento e a performance de Henrique que revisita sua trajetória de quando "fez a América", relembrando do episódio onde teve a oportunidade de cantar My Way com seu intérprete mais famoso: Frank Sinatra. A partir da fala de Henrique, que relata colocar frequentemente a música para ouvir e dublar, Coutinho pede, então, que ele repita o ritual para as câmeras. A performance emocionada de Henrique é celebrada pelo documentarista depois da gravação em comentários eufóricos com sua equipe: "ele cantando em plano fechado... ficção pura" e "documentário é isso! De repente pode tudo!"14.

Os diálogos que Coutinho produz nos abrem a possibilidade do contato com a alteridade, onde memórias e sentimentos alheios fazem sentido também ao se articularem com o nosso repertório. No contexto dos filmes que alternam falas e canções, desdobram-se outras camadas de significação. A presença da música propicia efeitos diversos durante a narrativa preponderantemente verbal dos filmes. Dessa forma, quebra-se o ritmo presente na racionalidade do discurso verbal por meio da evocação de aspectos mais abertos e amplos, da ordem da emoção. Ao mesmo tempo em que a música intensifica o valor do depoimento, ao aguçar o caráter dramático e emotivo das memórias, abre-se ao espectador a possibilidade de acessar suas próprias memórias e sentimentos. Além do discurso da canção em si, entram também em 
jogo aspectos que remontam ao contexto histórico daquelas músicas, dos autores, dos intérpretes e, a essas camadas, soma-se o contexto pessoal do espectador/ouvinte.

Se, como vimos, as trajetórias de vida, as oralidades e as memórias são a base do trabalho de Eduardo Coutinho, será em As Canções ${ }^{15}$, de 1999, que o autor levará às últimas consequências um dispositivo que já vinha se desenvolvendo em outros trabalhos. Trata-se de acessar a intimidade e a emoção dos personagens ao estimular, através da música, suas narrativas de "construção de si". As Canções é formado pelo conjunto de depoimentos e performances de diversos personagens que comparecem a um teatro para cantar e contar suas histórias de vida relacionadas àquelas músicas. Obviamente, não é a qualidade da performance dos intérpretes que importa, mas, novamente, a memória sentimental dos relatos que parece se atualizar e se intensificar com a presença do canto emocionado dos participantes.

Como as lembranças estão articuladas com as emoções vividas e, as músicas possuem pregnância na memória, o dispositivo mostra-se poderoso em recuperar e dar som e sentido àqueles relatos. Além disso, as performances das canções emocionam tanto os próprios depoentes quanto os espectadores. Como são, além de parte do repertório pessoal dos personagens, também pertencentes ao cancioneiro brasileiro, as músicas acabam permeando e articulando um rol amplo de forças subjetivas e objetivas. Vislumbra-se a relação com a indústria cultural que emana de uma trilha sonora histórica, eventualmente, relacionada à determinada classe social, em que emergem também determinados padrões estéticos e de consumo. Temos nessas canções, ademais, a força poética das letras e a lírica pulsante da trilha sonora da vida de cada um. 


\section{Referências}

APARTAMENTO 608 - Coutinho.doc. Direção: Beth Formaginni, Produção: 4ventos Comunicação. Rio de Janeiro: 4ventos Comunicação; Canal Brasil, 2009.

AS CANÇÕES. Direção: Eduardo Coutinho. Produção: João Moreira Salles, Mauricio Andrade Ramos. Rio de Janeiro: Videofilmes, 2011.

BOCA DE LIXO. Direção: Eduardo Coutinho. Rio de Janeiro: Videofilmes, 1993.

EDIFÍCIO MASTER. Direção: Eduardo Coutinho. Produção: João Moreira Salles, Mauricio Andrade Ramos. Rio de Janeiro: Videofilmes, 2002

LINS, C. O documentário de Eduardo Coutinho: televisão, cinema e vídeo. Rio de Janeiro: Zahar, 2004.

MAIA, G. Aspectos da música no documentário contemporâneo: algumas reflexões sobre o fazer e o pensar. Revista Doc On-line, Campinas, n. 12, ago. 2012.

OHATA, M. (Org.) Eduardo Coutinho. São Paulo: Sesc; Cosac Naify, 2013.

SACKS, O. Alucinações musicais: relatos sobre a música e o cérebro. São Paulo: Companhia das Letras, 2007.

SANTA MARTA - Duas semanas no morro. Direção: Eduardo Coutinho. Rio de Janeiro: Videofilmes, 1987.

submetido em: 13 ago. 2016 | aprovado em: 29 set. 2016 